\title{
«La hermana mayor»: las difíciles relaciones entre la marina mercan- te española y la Armada (1802-1932)*
}

\author{
Enric Garcia Domingo ${ }^{1}$ \\ Universidad de Barcelona \\ garciade@telefonica.net
}

RESUMEN: La marina mercante española estuvo supeditada a la marina de guerra, en muchos aspectos, entre principios del siglo XVI y la segunda mitad del siglo XX. En el origen de esta dependencia estaba la necesidad de disponer de la fuerza de trabajo procedente de la marina comercial para tripular los buques de guerra o nutrir los arsenales del Estado. De este modo, por ejemplo, el colectivo de trabajadores quedó supeditado al control de la Armada. Esta supervisión se ejercía básicamente a través de una institución, la Matrícula de Mar. Sus efectos sobre el colectivo de marinos mercantes (reserva de trabajo, mediatización del mercado laboral, control de la disciplina, jurisdicción especial por medio del fuero de marina, etc.) explican gran parte de las características de la vida y el trabajo en la Marina mercante en época contemporánea. Este artículo analiza los efectos de este control militar sobre un sector económico esencialmente civil y la lucha por separar ambas formas de administrar los asuntos marítimos. También aporta casos concretos del control ejercido por la Armada sobre el trabajo y los trabajadores.

* Trabajo realizado en el marco de dos proyectos de investigación, ambos con la Dra. Cristina Borderías como investigadora principal: «La reconstrucción de la actividad económica en la Cataluña contemporánea: trabajo, demografía y economía familiares» (HAR201126951) y «Crisis y reconstrucción de los mercados de trabajo en Cataluña (1760-1860). Ocupaciones, culturas del trabajo y estrategias adaptativas» (HAR2014-57187-P) financiados por el Ministerio de Economía y Competitividad. Se han empleado las siguientes abreviaturas: MMB (Museu Marítim de Barcelona), AGMAB (Archivo General de Marina Álvaro de Bazán), BC (Biblioteca de Catalunya), ACA (Archivo de la Corona de Aragón), AHCOCINB (Archivo Histórico de la Cámara Oficial de Comercio, Industria y Navegación de Barcelona) y AMNM (Archivo del Museo Naval de Madrid).

1 ORCID iD: http://orcid.org/0000-0002-1903-9779. 


\section{PALABRAS CLAVE: Marina de guerra; administración marítima; Ma- trícula de mar; marina mercante; historia del tra- bajo.}

«The Big Sister»: The Difficult Relationships between the Spanish Mercantile Marine and the Spanish Navy (1802-1932)

ABSTRACT: The Spanish merchant marine was subordinated to the navy, in many aspects, between the early sixteenth century and the second half of the twentieth century. The main reason was the need to control the workforce from the merchant navy to man warships or to nourish State arsenals. Thus, the collective of seamen was subordinated to naval control. This supervision was exercised primarily through an institution, the Matricula de Mar. It had a heavy effect on the merchant seamen: closed shop for Spanish seamen, control over the labour market, discipline control, a special naval jurisdiction for seamen, etc. It explains the main characteristics of life and work on board in the Merchant Marine in contemporary times. This article analyses the effect of this naval control over an essentially civilian economic sector and the struggle to separate the civil and the military way of administrate the maritime affairs. It also provides examples of the control over the workers exercised by the Navy.

KEY WORDS: Navy; Maritime Administration; Matricula de Mar; Mercantile Marine; Labour History.

CÓMO CITAR ESTE ARTÍCULO/CITATION: Garcia Domingo, Enric, «'La hermana mayor': las difíciles relaciones entre la marina mercante española y la Armada (18021932)», Hispania, 77/255 (Madrid, 2017): 217-249. doi: 10.3989/hispania.2017.008.

\section{INTRODUCCIÓN}

El objetivo de este artículo es analizar la relación entre la marina mercante y la marina de guerra en España, a veces conflictiva y desigual siempre. De entre los diferentes niveles en los que la Marina de guerra española mantuvo el control y una estricta supervisión de las actividades marítimas comerciales, me centraré en un punto de vista concreto, tal vez el más rico: el mundo del trabajo y de las relaciones laborales. Este foco permite detectar algunos de los puntos de fricción más importantes entre ambas marinas, y lo que es más importante, demostrar la sumisión de la marina mercantil a la Armada y sus necesidades estratégicas y materiales.

Si bien la tesis que mantiene este artículo precisa del análisis de un espectro cronológico amplio, ya que se trata de una relación que en sus características principales se extiende del siglo XVI al siglo XX, el estudio se centra sobre el periodo concreto que va de 1802 a 1932, límites que pivotan alrededor de dos momentos destacados en cuanto a la relación entre lo civil y lo militar. 
En 1802 se promulgaron unas Ordenanzas de Matricula que cristalizaron en un proceso de militarización de la marina mercante iniciado antes, y que define las relaciones entre ambas marinas a lo largo de gran parte del siglo XIX y en algunos aspectos hasta el primer cuarto del siglo XX. En cuanto a la fecha límite, la sitúo en 1932, cuando de la mano de la recién nacida II República, por primera vez en la historia de España, se creó por Ley de 12 de enero de 1932 una marina civil. Esta marina civil tendrá una corta vida y escasa influencia, abortada con el golpe militar de $1936^{2}$.

Este artículo tiene dos partes bien diferenciadas. En la primera analizaré el marco jurídico que permitió el control por parte de la Armada y revisaré los diversos intentos de separación entre las esferas civil y militar. En la segunda parte proporcionaré algunos ejemplos concretos de la influencia de lo militar sobre el mundo del trabajo en la marina mercante, como ejemplo de esta supeditación.

\section{¿HERMANA MAYOR O MADRASTRA?}

Desde principios del siglo XVI, el desarrollo de la Marina mercante española estuvo marcado por las necesidades del tráfico con las colonias americanas, que quedó organizado mediante el sistema de flotas y galeones, construido a partir de un estricto control desde el puerto de salida (Sevilla primero y Cádiz después) y desde los puertos coloniales ${ }^{3}$. La necesidad de organizar y tripular flotas, protegidas por convoyes, para realizar un comercio controlado, condicionó las formas de organización de la actividad comercial. Junto a esta necesidad, el mantenimiento de un sistema defensivo basado en buques de guerra que exigían numerosa tripulación, llevó a la supeditación de la marina mercantil a las necesidades del Estado. A partir de 1700 el nuevo régimen borbónico reorganizó la Marina ${ }^{4}$, sentó las bases, entre otras cosas, de la existencia de una auténtica marina de guerra nacional, y también consolidó el sometimiento de la marina mercante a la Armada en muchos aspectos. El siglo XVIII es un periodo de expansión comercial, pero también de conflictos armados que condicionaron el mundo del trabajo en la marina mercante, al ser los marinos mercantes la principal fuente de tripulantes para los buques de guerra. A lo largo del siglo XVIII y hasta el desastre de Trafalgar el espectro de la guerra fue constante. Pero la relación entre la Armada y la gente de mar

2 HERRÁN (2000).

3 Sobre este tema existe bastante bibliografía. Véase, entre otros, FERNÁNDEZ DURO, 1973; CHAUNU, 1983; GARCÍA-BAQUERO Y MARTÍNEZ-SHAW, 1992; PÉREZMALLAÍNA, 1992, y MARTÍNEZ SHAW, 2008.

4 Véase bibliografía sobre este periodo en CEPEDA, 2008. 
no se limitó al contexto de las guerras napoleónicas. En realidad, el siglo XIX presenció diversas situaciones en las que la Armada, pese a su precaria situación, se vio implicada en operaciones militares internas y externas y, por tanto, precisó de personal para el servicio de sus buques y arsenales. Miles de hombres fueron llamados a filas para participar en las campañas de la Independencia Americana, en las guerras carlistas, en la represión de movimientos cantonales, en la protección del tráfico marítimo colonial, en las guerras de África, en la represión del contrabando en las costas españolas o de la piratería en aguas filipinas, en la protección de los intereses comerciales de ciudadanos españoles en el Río de la Plata, México o Perú, en las guerras en Cuba y Filipinas, etcétera. Por tanto es imposible comprender el funcionamiento de la Marina mercante en el lapso temporal propuesto y, especialmente, el mundo del trabajo en este sector, sin considerar su relación con la marina de guerra.

\section{La fuerza de trabajo como base de las tripulaciones de los buques de guerra}

Para garantizar su existencia y su eficacia, la Marina de guerra española, como la de otras potencias europeas del pasado, precisaba del concurso de miles de hombres, que eran empleados como tripulación en todo tipo de buques de guerra y también para su construcción en los arsenales del Estado. Junto con un número limitado de marinos de guerra profesionales (y utilizo este término consciente de su imprecisión en ciertos períodos), debía asegurarse la concurrencia constante de miles de hombres, preferentemente profesionales de la mar, es decir, gente que en su vida civil trabajaba en la navegación de cabotaje o de altura, en la pesca o en astilleros particulares. Con el nacimiento de los Estados modernos hizo evidente que era necesario algún sistema que permitiese controlar aquel potencial para que fuera útil para cubrir sus necesidades de personal, junto con la supervisión de astilleros, puertos, materias primas estratégicas, etcétera.

El instrumento ideado era una institución denominada Matrícula de Mar ${ }^{5}$, que se puede definir como un contrato entre la Corona y una parte de sus súbditos basado en un teórico equilibrio entre derechos y deberes pero que no era negociable: se aceptaba con todas sus consecuencias o se rechazaba. ${ }^{6}$ Francia,

5 Sobre la institución de la Matrícula de mar y la legislación relacionada con ella, las principales fuentes son: SALAS, 1870; FERRET, 1819; LLOVET, 1980; LÓPEZ y MIRABET, 1995; VÁZQUEZ LIJÓ, 2007. Sobre el reclutamiento en la marina en general, GUTIÉRREZ DE LA CÁMARA, 2009.

6 En Francia, el equivalente recibía el nombre de Inscripción Marítima, que tenía las mismas raíces que la Matrícula de mar y, en consecuencia, un desarrollo similar (LENHOF, 2006). 
con las Ordenanzas de 1668 y 1681, y España, con la legislación que se comentará más abajo, pusieron en práctica sus matrículas enmarcadas en sendos programas de rearme naval. Este peculiar sistema de corte militar caracterizaba el trabajo en la marina civil y la diferenciaba de cualquier otro ramo de la actividad económica, ya que sujetaba todos sus aspectos a la jurisdicción militar y constreñía la vida de los trabajadores de la mar (según la definición tradicional, los «hombres de mar») a lo largo de toda su vida activa ${ }^{7}$. La otra gran Armada en competencia, la británica, se abasteció de personal por diversas vías, siendo dos las más usadas la leva forzosa (el caso paradigmático del impressment) y el voluntariado ${ }^{8}$. En Gran Bretaña se había intentado un sistema de registro similar en 1583, pero no cristalizó como el sistema francés o el español ${ }^{9}$.

En fecha tan temprana como 1606, se puso en marcha para los marinos españoles un primer sistema de registro voluntario en su puerto de residencia, de manera que pudiesen ser localizados y reclutados en caso de necesidad, pero no tuvo un impacto apreciable ${ }^{10}$. La primera Matrícula propiamente dicha fue establecida por la Real Cédula de 31 de octubre de $1625^{11}$. Este primer intento fracasó, pese a que la contrapartida al servicio eran diversos privilegios y exenciones, como quedar fuera de la recluta de quintas, libres de la obligación de alojar soldados, y exentos de cargas concejiles, es decir, de ejercer como alcaldes o como concejales. Estos privilegios no compensaban probablemente el hecho de estar en una lista de disponibles que podían ser enviados a campañas de tres o cuatro años, o que veían su libertad de movimiento constreñida. A partir de 1700, la nueva administración de inspiración francesa estableció normas más rigurosas y moderadamente eficaces para garantizar el reclutamiento de hombres a partir de la organización del territorio, entre otras cosas. En una Real Orden de 29 de agosto de 1726 se establecieron los tres Departamentos en que se dividía el territorio nacional (Ferrol, Cádiz y Cartagena, subdivididos en provincias marítimas y otras unidades administrativas menores) para un mejor registro y el control de la gente de mar y maestranza en dichos territorios. En esta misma Real Orden se reiteraba a la gente de mar la oferta para que se alistase a cambio de «la libertad de no

7 Uno de los pocos sectores donde lo militar ha tenido una estrecha relación con lo civil es en los ferrocarriles españoles, especialmente desde la constitución de RENFE, en 1941 (GAGO, 2006:7-8).

8 Zeferino Ferret cita casos de reclutamiento forzoso en España con motivo de la guerra contra Inglaterra en 1779, cuando se llegó a arrancar a la fuerza a marineros de servicio en buques mercantes particulares «sin admitir excusas ni pretextos», hasta el punto de que se dejaron en la mar buques abandonados sin tripulación (FERRET, 1819:99).

9 DIXON, 1981.

10 Ordenanza de Felipe III el 4 de noviembre de 1606, transcrita en SALAS, 1870:74-77.

11 Impreso fechado en Madrid en 1625. AMNM. 
entrar en sorteo de quintas para la recluta o aumento de mis ejércitos de tierra» $\rangle^{12}$.

Un cambio fundamental tuvo lugar a raíz de la Instrucción de 4 de noviembre de 1737 (conocida como «Ordenanza del Infante Almirante»), cuando por primera vez se declaraba la exclusividad de los matriculados en los oficios marítimos, principio que desvirtuó el carácter pretendidamente voluntario de la Matrícula. ${ }^{13}$ Además, fijó por primera vez unos límites de edad (entre los 14 y los 60 años) para matricularse y estableció las causas de exclusión. En 1748, se publicó otra Ordenanza de la Real Armada, sin apenas efecto, que fue seguida en 1751 por una nueva disposición, esta sí, decisiva para el proceso de institucionalización de la Matrícula. En ella se consolidaban los elementos fundamentales de la Matrícula, que se mantuvieron durante un siglo: el registro obligatorio a cambio de unas ciertas franquicias y sobre todo la exención de quintas de reclutamiento para los ejércitos de tierra y el Fuero de Marina, un escudo jurisdiccional para los alistados ${ }^{14}$. Como efecto colateral también supuso la intervención de los gremios de mar y su desarticulación hasta dejarlos limitados a funciones de orden asistencial y poco más ${ }^{15}$.

La culminación en el desarrollo legal de la institución de la Matrícula de Mar, y con ella del papel controlador de la Armada sobre los trabajadores del mar, se alcanzó con las Ordenanzas de la Matrícula de Mar de 1802, que estuvieron vigentes hasta 1873. Entre otras cosas, la Matrícula pasó a ser controlada por los oficiales del Cuerpo General de la Armada. Se trataba del final de un proceso iniciado con un Real Decreto de 25 de abril de 1800, que confirmó la pérdida de peso ejecutivo de los hombres del cuerpo del Ministerio de Marina en favor de la oficialidad militar, el cuerpo General de la Armada. Fue «un traspaso de competencias desde la pluma hacia la espada que vendrá acompañado de una nueva reordenación administrativa ${ }^{16}$. Uno de sus principales críticos fue el general Antonio de Escaño, quien estaba convencido de que los Ayuntamientos hubieran bastado para llevar un padrón exacto de toda la marinería y de que podía quitársele esa atribución a la Marina ${ }^{17}$.

La Matrícula de Mar regulaba la vida del colectivo de la gente de mar (marinos mercantes, pescadores y carpinteros de ribera y descargadores de puerto) en cuanto a sus obligaciones con el Estado. Si bien es cierto que la gestión

12 Documento citado por FERNÁNDEZ DURO, 1973, vol. 6: 228.

13 SALAS, 1870:167 y ss.; VÁZQUEZ LIJÓ, 2007:243.

14 En VÁZQUEZ LIJÓ, 2005:255.

15 En COLLDEFORNS, 1951. En los estatutos del gremio de mareantes de Arenys de Mar se explicitaba la subordinación total del gremio a las autoridades de Marina (véase Estatutos generales del gremio de Arens [sic] de Mar. 27 de noviembre de 1828, MMB, Colecciones, documento núm. 2.361).

16 VÁZQUEZ LIJÓ, 2007:27.

17 ESCAÑO, 1820:44-46. 
del negocio marítimo de la organización del trabajo a bordo de los buques quedaban por completo en manos del armador y del patrón o capitán, la injerencia del Estado en el mercado de trabajo mediante el control de la disponibilidad de los marineros resultó muy conflictiva. Y no sólo eso. Aunque la Armada quedaba aparentemente en segundo plano, controlaba algo tan importante como la disciplina y muchos otros aspectos que se apuntarán en la segunda parte de este ensayo. Canuto Corroza, en el comentario histórico que abre su proyecto de reforma redactado en 1865, repasa el proceso de constricción de los marinos. Según este autor, en las primeras Ordenanzas (1625, 1726), no se establecía un fuero especial ni se monopolizaba ninguna actividad; únicamente se ofrecían ciertas ventajas para atraer a marinos voluntarios al servicio militar, pero sin ningún menoscabo para su libertad. Sin embargo, en ordenanzas posteriores $(1737,1748,1751$, y sobre todo en la última, de 1802), la presión sobre los hombres de mar se acentuó. En palabras de Corroza: «En lugar de ofrecer aliciente para que voluntariamente se alisten en el servicio, se manda matricular toda la gente de mar, bajo pena de dejar de ser gente de mar; no hay, pues, libertad, hay usurpación de los derechos naturales $[\ldots]\rangle^{18}$. Así, la libre concurrencia al mercado y la libertad de contratación quedaban limitadas.

La Matrícula estaba abierta a todos los españoles (o naturalizados) y católicos. Había una destacada excepción: la comunidad chueta de Mallorca, descendiente de judíos conversos, considerada indeseable ${ }^{19}$. Al margen de esta señalada exclusión, es importante destacar que el régimen de la Matrícula de mar no afectaba a todos los españoles por igual. Las islas Canarias, las provincias vascas, algunos puertos cántabros, la Albufera de Valencia y los presidios africanos quedaban exentos de la misma. En la costa vasca estuvo vigente un sistema particular de listas, nominativas en Guipúzcoa y numéricas en Vizcaya. La contribución de los puertos del País Vasco a las levas de los buques de la Corona era proporcional a la gente disponible y a las necesidades de armamento, y las reclutas corrían por cuenta de las Diputaciones mediante el sistema que juzgasen más conveniente. Este régimen privilegiado era consecuencia de la protección de los Fueros, y duró hasta su abolición, en julio de 1876, al final de la Tercera Guerra Carlista. Mientras se mantuvo, dio un gran margen de maniobra a los gremios de «mareantes» vascos, y sin duda influyó en la formación del carácter de la marina vascongada en los siglos XIX y XX. Diversos testimonios apuntan a que, con el sistema de cupos, las provincias vascongadas disponían de la mejor y más abundante marinería, sin

18 En CORROZA, 1865:33-34.

19 ZALVIDE, 1773: 104-105 y 110-111. Tampoco les consideraba aptos para ejercer los oficios relacionados con la construcción naval. 
dejar por ello de acudir al servicio de la Armada, mientras que la marina decaía en otras zonas del país ${ }^{20}$.

La progresiva militarización de la gente de mar y de maestranza (constructores navales) en el desarrollo de su actividad profesional quedaba patente en diversas restricciones, como la obligación de estar permanentemente a disposición de las necesidades de la Armada, la restricción en la libertad de movimientos, la necesidad de permisos especiales para realizar cualquier desplazamiento, la facilidad con que se les atribuía el delito de deserción si no estaban localizados, y también el carácter de las penas que se les imponía por el incumplimiento no solo de lo reglamentado en la Matrícula, sino también de sus obligaciones laborales en sentido amplio. Son fáciles de imaginar las consecuencias para la gente de mar, desde el punto de vista personal y también desde el punto de vista de la imposibilidad de acudir al mercado de trabajo a causa de las obligaciones para con la Marina de guerra. Por otro lado, la marinería acababa siendo poca y mala a causa de las deserciones, el fraude, la corrupción en la administración, etc. Esta situación sin duda puede explicar en parte los fracasos de la Armada Real en los años finales del siglo XVIII, y hasta Trafalgar ${ }^{21}$.

Conviene insistir en que, a diferencia de lo que sucedía con el servicio militar en el ejército, que tenía un límite temporal, la Matrícula de Mar ligaba al marino durante todo su ciclo de vida activa hasta los 60 años. Para comprender el impacto de esta dependencia sobre la vida y el trabajo, podría hacerse un símil con lo que supondría someter de por vida a las necesidades del Ejército a todas aquellas profesiones que presentan un valor estratégico, como los arrieros o las guarnicioneros para la Caballería, los fundidores o los carreteros para la Artillería, los albañiles o los mineros para el Cuerpo de Ingenieros, etcétera, profesionales todos que no se veían sujetos a un servicio permanente en el Ejército de Tierra. Esto sucedía, entre otras cosas, por la desproporción en el impacto del reclutamiento sobre la población masculina. Por ejemplo, estos son los datos relativos al año 1857: se preveía un contingente para servir en la Armada de 10.732 hombres; de ellos, 9.424 para embarcarse, 1.006 para los depósitos y arse-

20 Sobre los marinos vascos, el valor que representaban para las necesidades de la Armada y su tratamiento privilegiado, véase Representación que el Consulado Nacional del Comercio de la Isla de Mallorca ha dirigido a S. M. Las Cortes: haciendo ver la necesidad de la abolición de las Matrículas de Mar en la Península e islas adyacentes, 1814; Exposición dirigida al Excmo. Sr. Ministro de Hacienda, por la comisión nombrada por todas las clases de Santander, solicitando el planteamiento de las reformas marítimas que deben ser el complemento de la supresión del derecho diferencial de bandera para las importaciones terrestres. Santander: Imprenta y Litografía de J. M. Martínez, 1867:1-10 y 43; SALAS, 1870:53-63 y 89-101.

21 Sobre esta interpretación véase CORROZA, 1865: 70-75 y 80; SALAS, 1870: 225; MARTÍN GARCÍA, 1999, 427-428. 
nales y 302 para tripular los cuatro vapores que prestaban servicio de correo a las Antillas. Este contingente se cubría con la concurrencia de los individuos matriculados (que se cifraba en 80.787), mientras que el contingente de aproximadamente 70.000 hombres previsto para cubrir todas las necesidades del Ejército se nutría con la concurrencia del resto de los mozos del país, que sumaban unos 13 millones ${ }^{22}$. Además, hay que recordar que a los 10.732 matriculados movilizados para su inmediata incorporación hay que sumar aproximadamente 3.200 individuos «embargados», es decir, que no se incorporaban a filas pero se hallaban movilizados de facto, además de otros cuantos centenares que permanecían con sus movimientos limitados ${ }^{23}$.

Esta desproporción se traducía en una sobrecarga de servicios para la gente de mar y probablemente tenía un impacto sobre el mercado de trabajo que todavía no estamos en condiciones de documentar. La alternativa generalmente propuesta era que se hiciera un reclutamiento para la Armada por el sistema de quintas, como en tierra, visto que la exención de quintas que venía asociada a los privilegios de los matriculados se tornaba en realidad en una obligación aún peor. Un artículo publicado en 1878 resumía dramáticamente la relación entre un hombre de mar y la Armada:

Se embarcan niños con sus padres y parientes, ejerciendo la pesca y los primeros rudimentos del oficio. Siendo jóvenes pasan a los buques de guerra a su primera campaña por dos o tres años. A menudo después de su campaña saben leer y escribir, cuartear la aguja y se embarcan como compañeros en buques de comercio. Cuando se incorporan para una segunda campaña tienen ya experiencia y pueden ser gavieros, timoneles, etc., y también «hombres de doble oficio»: cabos de cañón, marineros, tiradores, fogoneros, etc. La tercera campaña la cumplen hombres con 45 a 50 años. Concluida la tercera campaña, toman licencia como veteranos con 8 o 9 años de servicio. En compensación a esta perpetua dependencia y continuados deberes, les corresponde el ejercicio exclusivo de las industrias marítimas» ${ }^{24}$.

22 Estos datos en Memoria sobre los vicios de que adolece la ordenanza de Matrículas de Mar de 1802, y la necesidad de proceder cuanto antes a su abolición, sustituyéndola con otro sistema que en armonía con las instituciones políticas del país, atienda al sostenimiento de sus fuerzas navales, sin abrumar con trabas y vejaciones a la marina mercante, Palma, Imprenta de Pedro José Gelabert, 1856, 18 y ss.

23 Incluso desaparecida la Matrícula, un Real Decreto de 7 de enero de 1879, en su artículo $5 .^{\circ}$, disponía que no se permitía a los marinos con edades comprendidas entre los 15 y los 35 años el dirigirse al extranjero, sin previamente depositar 2.000 pesetas en garantía para quedar obligado al servicio de las armas, es decir, para prevenir deserciones. Aunque la medida excluía a los que se dirigían a las provincias españolas de Ultramar, no deja de suponer una carga y una limitación para los hombres de mar.

24 Artículo firmado por F. de S. y H. en Revista Marítima, núm. 12, 20 de abril de 1878. 


\section{Extensión del liberalismo económico}

La dependencia de la marina mercante española respecto a la Armada es cuestionada de forma paralela a la crisis del Antiguo Régimen y a la extensión del liberalismo económico. A lo largo del siglo XIX la institución de la Matrícula fue contestada por unos y defendida ferozmente por otros. En especial después del final de la Guerra de Independencia y de la emancipación de las colonias americanas, cuando la Armada estaba desaparecida virtualmente, la presión fue aumentando de forma progresiva. En ciertos aspectos, la lucha por su abolición siguió un camino paralelo al de la que pretendía también la eliminación de las quintas, ya que ambas formaban parte de los programas democráticos y republicanos. ${ }^{25}$ Sus intereses coincidían con los de armadores y comerciantes que exigían la liberalización del mercado de trabajo y la abolición de las estructuras del Antiguo Régimen. Por el otro lado, la institución fue defendida por la Marina y, en parte, también por los propios matriculados. ${ }^{26}$ La defensa de algunos privilegios, como por ejemplo la reserva de los trabajos de carga y descarga en los puertos, apunta a una posición en general favorable al menos de una parte de los matriculados ${ }^{27}$.

El proceso de supresión de la Matrícula fue largo y accidentado. Suprimida por primera vez por las Cortes de Cádiz en $1812^{28}$, vivió una corta restauración en la década ominosa y vuelve a desparecer durante el Trienio Liberal, cuando en 1820 se transfirió la jurisdicción del reclutamiento de la marinería a los Ayuntamientos. ${ }^{29} \mathrm{La}$ experiencia resultó un caos sin apenas efectos positivos $^{30}$. Años más tarde, coincidiendo con la redacción de una nueva constitución liberal (que no llegó a promulgarse) en 1856, se inició una ofensiva contra la Matrícula, por «incompatibles las exigencias del régimen impuesto por la

25 BONAMUSA y SERRALLONGA, 1995.

26 IBARZ y ROMERO, 2009:257.

27 Cuando en abril de 1870 estalló en Barcelona una insurrección en la que la protesta contra las quintas y las Matrículas era uno de los argumentos fundamentales, los principales disturbios se dieron en las poblaciones de Sants y Gracia; en cambio, apenas hubo problemas en la Barceloneta, el barrio marinero de la ciudad, donde con toda probabilidad residía el mayor número de matriculados y donde la población era tradicionalmente muy proclive a las revueltas populares. Resulta sorprendente que en una ocasión tan propicia a la protesta contra las Matrículas aquel distrito se mantuviera tranquilo (IBARZ y ROMERO, 2009:263).

28 Las Cortes de Cádiz, «atendiendo á que las Matrículas de mar en las provincias de América y Asia son inútiles», las abolieron con un decreto de 15 de enero de 1812 (Memoria sobre los vicios..., 52). También se presentó ante las Cortes, el 18 de febrero de 1814, por parte de miembros del Consulado de Comercio de Mallorca, un documento a favor de la abolición de las Matrículas, que fue publicado con el título de Representación que el Consulado Nacional del Comercio de la Isla de Mallorca ....

29 COLLDEFORNS, 1951:76.

30 SALAS, 1870: LIII y LIV. 
Matrícula de Mar con los principios de equidad y justicia en que descansan las instituciones liberales» ${ }^{31}$. En 1861 se presentó un nuevo proyecto de Ordenanza de Matrícula, que planteaba una reforma de la antigua Ordenanza de 1802 aunque manteniendo sus rasgos principales ${ }^{32}$.

En las actividades marítimas los esquemas del Antiguo Régimen se mantuvieron vigentes hasta que en 1868 la legislación liberal rompió definitivamente ese marco en lo relativo a las actividades marítimas, aunque sin conseguir eliminar por completo el control de la Armada. La lucha contra la Matrícula debe enmarcarse en un proceso más amplio que tiene, en el sector marítimo, hitos fundamentales como las leyes de 1868 de Laureano Figuerola. Los principios doctrinales del liberalismo económico propugnaban, entre otras reivindicaciones: libertad e igualdad formal ${ }^{33}$, abstencionismo legislativo e imperio de la autonomía de la voluntad individual. Lo que se pretendía era, obviamente, hacer posible la libre contratación de la fuerza de trabajo que requería el capitalismo en expansión. Una institución del Antiguo Régimen, como era la Matrícula de Mar, y en general la tutela de la Marina de guerra, constituían un obstáculo para este proceso.

Por otro lado, el proceso de desaparición de la Matrícula coincidió en sus momentos de mayor de intensidad con la progresiva implantación de la propulsión mecánica en la marina mercante y los cambios en la organización del trabajo que el desarrollo tecnológico supuso para los trabajadores de la mar. En 1863, el citado ingeniero Canuto Corroza redactó un influyente informe, de corte liberal, con propuestas diversas sobre la organización de los asuntos marítimos en España, en un intento de modernizar un marco legislativo obsoleto, ineficiente y poco adecuado para una marina en constante renovación en el contexto de la industrialización. Su exposición, firmada con fecha del 17 de septiembre de 1863, circuló fluidamente entre los círculos marítimos, hasta el punto de que en verano de 1864 diversas Juntas de Comercio se manifestaron en apoyo del proyecto de Corroza y a favor de la supresión de las Matrículas $^{34}$. Esta propuesta de Corroza fue publicada en 1865 con el título Estudios

31 Memoria sobre los vicios..., 13, 40-41 y 48-49.

32 Proyecto de Ordenanza para el régimen y gobierno de las Matrículas de Mar: formulado por la Comisión especial nombrada de Real Orden y presentado por su presidente, el de la Junta Consultiva de la Armada. Madrid: Imprenta de Luís Palacios, 1864.

33 La libertad contractual entre empresario y trabajador, entre capital y trabajo, se consideraba basada en el principio de igualdad formal ante la ley, mientras que se tenía por irrelevante la desigualdad material entre dichas partes (CASTILLO, 1992:152).

34 Proyecto de contestación de la Sección de Comercio de la Junta de Barcelona con fecha 14 de agosto de 1864 y dictamen de la Junta Provincial de Valencia, de fecha 1 de septiembre de 1864. BC, Fondo de la Junta de Comercio de Barcelona. Legajo CXXXIII. Caja 176, carpeta 2. En ambos casos se apoya el proyecto de Corroza, aunque se considera que hay que discutir algunos detalles menores. En la misma línea, la Junta de Comercio de Cádiz hizo 
sobre una ley para el uso general del mar, para la navegación y para los puertos. Además de una memoria histórica sobre la Matrícula de Mar y un análisis de la legislación entonces vigente, la obra incluye un Proyecto en el cual encontramos resumidos los elementos claves de la ofensiva liberalizadora: abolición de las Matrículas, disolución de gremios de mareantes, cese del fuero y la jurisdicción de Marina, abolición de todas las disposiciones de las ordenanzas de Marina que no se refieran directa y exclusivamente al servicio militar de la Armada, y reclutamiento de tripulaciones de reemplazo según lo que disponía la ley de 26 de enero de 1856 para el reemplazo del Ejército, en quintas anuales. Pese a su oportunidad y la solidez de sus argumentos, el proyecto de Corroza no prosperó debido a la resistencia de la Armada; por tanto, la Marina mercante española siguió dependiendo durante décadas de un cuerpo legislativo incompleto y deficiente. En cambio, lo que sí provocó el texto de Corroza fue la reacción del capitán de fragata y miembro de la Academia de la Historia Francisco Javier de Salas, quien difundió años más tarde un encendido alegato en defensa de la Matrícula de Mar, un documento de gran valor histórico y analítico que fue publicado por el Ministerio de Marina en $1870^{35}$.

La Matrícula fue reformada, aunque no abolida, por un decreto del 27 de noviembre de 1867 , como medio para disminuir la presión en un momento políticamente conflictivo ${ }^{36}$. Sin embargo, la reforma llegaba tarde y poco después, durante la Primera República, el régimen de la Matrícula de Mar fue abolido. Fue una de las consecuencias del sexenio revolucionario y resultó un acto sorprendentemente rápido y exento de dramatismo en su momento final, pese a la virulencia de los debates desatados en los años precedentes ${ }^{37}$. La promulgación de la Ley de Inscripción Marítima de 22 de marzo de 1873 abolió definitivamente la institución de la Matrícula de Mar que, recordemos,

circular un impreso fechado el 12 de julio de 1864 solicitando la supresión de las Matrículas, para su firma y envío al Gobierno. En otro lugar (Respuesta al cuestionario dirigido a los constructores de barcos de madera, de máquinas de vapor, armadores y comerciantes. $\mathrm{BC}$, Juntas Provinciales de Agricultura, Industria y Comercio. Expediente 3- Informes y servicios. 1886. JC 246-11.) se dice literalmente: «un excelente trabajo que esta Corporación se abstiene de recomendar porque él por sí solo se recomienda notablemente a la ilustrada rectitud de esa Comisión».

35 Sobre su publicación se dio noticia en la Gaceta de Madrid de 25 de agosto de 1870 en un «parte no oficial». Véase la reseña biográfica de Salas en El Mundo Naval Ilustrado, núm. 49, 1 de mayo de 1899, 166-168.

36 Decreto reproducido en La Marina Española, núm. 5, de 1 de diciembre de 1867. En otro número de la revista (núm. 21, de 6 de marzo de 1868), se presenta una copia literal de las Instrucciones sobre el Real Decreto de 27 de noviembre de 1867 acerca de la reforma de Matrículas y servicio de mar, de 27 de febrero de 1868.

37 Más detalles sobre el debate parlamentario y, en general, sobre el proceso que llevó a la abolición de la Matrícula en IBARZ, 2008:23-36. 
tenía sus raíces en la primera década del siglo XVII. La Inscripción Marítima (regulada posteriormente mediante la Ley de Reclutamiento y Reemplazo del Personal de Tripulación de los Buques de la Armada, de 17 de agosto de $1885^{38}$ se constituyó como el único sistema de reclutamiento militar pero el problema, desde el punto de vista laboral, no se resolvió por completo ya que la desmilitarización no fue total. La abolición de dicha institución del Antiguo Régimen no supuso ningún cambio desde el punto de vista disciplinario, ya que una Real Orden de Marina de 16 de marzo de 1878 declaró vigentes todos los artículos del Título XIV de la Ordenanzas de Matrícula de 1802 referente a la disciplina, y no hubo producción legislativa nueva en este campo hasta la promulgación del Reglamento de disciplina y policía a bordo de los buques mercantes españoles de 18 de noviembre de 1909, de escaso alcance por otro lado.

Como se ha dicho, la pervivencia de la Matrícula y lo prolongado del proceso que llevó a su abolición se explican por la resistencia de la Armada en defensa de sus posiciones. Una vez abolido aquel sistema de registro se levantaron escasas voces que abogaron por su restauración, debidamente reformada: Francisco Javier de Salas, Jesús Cora, José Marcelino Travieso, Ricardo Caballero, José Ricart (con matices), etcétera ${ }^{39}$. Paradójicamente, también los navieros se manifestaron en favor del regreso de la Matrícula, o por lo menos utilizaron este argumento en alguna ocasión, incluso contradiciéndose, según los intereses de su estrategia en cada momento. En la década de 1880 reclamaban una matrícula o un sistema equivalente, cuando unas décadas antes a esta institución se le había atribuido todos los males de la Marina española ${ }^{40}$. Pero en el último cuarto del siglo XIX, con una marina velera en plena decadencia y una marina de vapor que definía un nuevo escenario de relaciones laborales, los avances sociales tenían que venir de la mano de la reforma social y no del parcheado de unas normas del siglo XVIII. Con todo, el recuerdo de la Matrícula estuvo presente durante años, y su retorno fue propuesto de forma esporádica, aunque cada vez con menor intensidad.

38 Gaceta de Madrid, núm. 23, de 20 de agosto de 1885.

39 Sobre la postura de la asociación El Fomento de la Marina Española en este asunto, véase Extracto de la Información escrita preliminar del congreso convocado por la Liga Marítima Española. Madrid, Imprenta de la sucesora de M. Minuesa de los Ríos, 1901, 101-102.

${ }^{40}$ Información sobre las consecuencias que ha producido la supresión del Derecho Diferencial de Bandera y sobre las valoraciones y clasificaciones de los tejidos de lana, formada con arreglo a los artículos 20 y 29 de la ley de Presupuesto de año de 1878-79, por la Comisión Especial Arancelaria creada por Real Decreto de 8 de septiembre de 1878. Tomo III. Industrias lanera y naviera. Discusión y aprobación de los dictámenes. Madrid, Imprenta de Manuel Minuesa de los Ríos, 1883. Información oral. Vigésima sesión, celebrada el día 14 de mayo de 1880. Intervención de Laureano Figuerola, 826-827. En el texto se acusa a los navieros de mantener una cosa y la contraria en breves períodos de tiempo, en un intento desesperado de frenar el proceso liberalizador. 


\section{Reescribiendo las relaciones entre ambas Marinas}

La abolición de la Matrícula y un marco legislativo liberal permitieron el desarrollo de la actividad de la Marina mercante en un nuevo escenario, pero dejó sin resolver algunos de los problemas planteados tradicionalmente. Una gran parte de la actividad del sector continuaba bajo la supervisión más o menos cercana de la Marina de guerra, mientras que los aspectos más importantes relacionados con el trabajo y su organización pasaron a regularse mediante una legislación civil confusa. Desde el punto de vista del trabajo, en el último cuarto del siglo XIX y el primero del siglo XX destacan tres grandes cuestiones: la fricción entre las marinas mercante y de guerra, la reforma administrativa en el ámbito de los asuntos marítimos, y la reforma social.

La supresión de la Matrícula de Mar no acabó con la presencia de la Armada en las actividades mercantiles. La relación entre ambas marinas tenía todavía repercusiones negativas directas sobre el mundo del trabajo y sobre la gestión del negocio naviero, y por tanto se empezó a plantear de forma clara y directa la conveniencia de independizar la Marina mercante de la de guerra. Probablemente la primera vez que se propuso de forma pública esta separación fue en el Congreso Español de Geografía Mercantil y Colonial, celebrado en el Paraninfo de la Universidad Central de Madrid en noviembre 1883, donde se votó, a iniciativa de los navieros bilbaínos, ultra liberales, la creación de una Dirección General de la Marina Mercante dentro del Ministerio de Fomento, pero finalmente la Asociación de Navieros de Barcelona, enrocada en una política proteccionista, enmendó la propuesta, pidiendo que se situara dentro del Ministerio de Marina ${ }^{41}$.

Unos años después, en 1885, Cayetano Leygonier propuso la fundación de una Asociación Nacional para el Fomento de la Marina; en sus estatutos se decía explícitamente que debía procurarse el fomento paralelo de la marinas mercante y la de guerra, cuyos intereses se ligan «hasta el extremo de completarse en su existencia y desarrollo ${ }^{42}$. Este discurso de la hermandad de ambas marinas era habitual en la prensa de la época, en términos similares. Buena muestra de los argumentos a favor o en contra es un debate concreto abierto por un alto oficial de la Armada, Víctor Concas, un firme partidario de

41 RICART, 1901b: 291; NARIZ DE LA BARCA, 1900:8. Una biografía de Ricart en MORENO (2013). Ricart Giralt ha presentado ese Congreso como una auténtica cruzada contra la Marina militar donde, declara, él mismo defendió la causa de la Armada junto con otros destacados personajes. Frente a ellos se atrincheraban figuras como Figuerola, Labra, Rodríguez, Alonso, Villavaso y, sobre todo, Joaquín Costa, quien mostró una actitud muy agresiva contra la Marina de guerra (RICART, 1907: 652-53). Sobre el pensamiento de Joaquín Costa en esta materia, véase COSTA, 1912

42 En LEYGONIER, 1885. En sus estatutos se definía una propuesta que aparece como un antecedente directo de lo que luego acabó siendo la Liga Marítima Española. 
la unión entre ambas. Aseguraba Concas que la Marina mercante necesitaba ser dirigida y administrada, y que los marinos de guerra eran los auténticos protectores de la marina comercial:

Los generales de la Armada que tiene su destino en el Ministerio, aunque malviven allí de sus sueldos, siendo los únicos hombres de mar que hay en la capital de la Monarquía, los únicos que pueden tratar los intereses de la Marina con conocimiento de causa, y si la Marina mercante no ha visto satisfechas muchas de sus aspiraciones, es porque pocas veces ha acudido para ello al Ministerio de Marina [...]. La marina militar no puede menos de mirar con cariño a personal cuyos sacrificios y cuyas penalidades conoce, por experiencia en analogía de profesión [...]. Y en esta afinidad está la razón más poderosa de intereses comunes...43.

Se trataba, pues, de una visión paternalista y condescendiente en la que la Armada se ocupaba de su «hermana pequeña», utilizando una expresión muy popular entre los círculos navales. El argumento opuesto puede resumirse en una respuesta a las palabras anteriores, una nota firmada por «Un marino mercante», que encontramos publicada en el Mundo Naval Ilustrado ${ }^{44}$. El autor anónimo de la réplica no creía en la necesidad de una unión entre ambas marinas y recordaba que en naciones más destacadas en cuanto a marina militar y comercial, pese a no estar ambas unidas, la mercante no ha dejado de contribuir con personal y material en caso de guerra, y se reafirma en las aspiraciones de dejar de depender del Ministerio de Marina. Sin duda, en la mente de quienes pensaban como el comentarista estaba el modelo británico, en el cual pese a la interacción entre ambas marinas, los asuntos comerciales (y laborales) de la marina mercantil eran administrados por un aparato civil plenamente independiente. Ricart Giralt, pese a ser un firme defensor de la unidad, no podía menos que lamentarse:

Si el Sr. Concas fuera marino mercante y al llegar a algunas Comandancias de marina fuera recibido como un grumete, con su bien cortada pluma demostraría que la marina militar más bien trata como hijastra a la Marina mercante que como hermana, que es lo que desearíamos ${ }^{45}$.

El enfrentamiento entre marina civil y marina militar era constante y desigual. Existían, además de intereses, sensibilidades. Por el lado civil se experimentaba una sensación de maltrato y de opresión, mientras que la Marina de guerra consideraba a los mercantes inconscientes y desagradecidos. Desde

43 En CONCAS, 1900: 488-491. Se trata de una carta dirigida a Gonzalo de Artaza, presidente de la Asociación de Capitanes y Oficiales de la Marina Mercante.

44 En El Mundo Naval Ilustrado, núm. 34, 20 de diciembre de 1900, 540-542.

45 El Mundo Naval Ilustrado, núm. 34, 20 de diciembre de 1900, 541-542. 
el paternalismo dominante se veía a los marinos mercantes como gente que no valoraba lo que la Armada hacía por ellos, y que en la época en que se cuestionaba la Matrícula habían jugado la carta equivocada. Según el citado Víctor Concas, precisamente los capitanes y los pilotos fueron de los que más trabajaron para la supresión de las Matrículas de Mar: «recuerdo todavía cómo gritaban como energúmenos ¡abajo las Matrículas! ${ }^{46}$. Con él coincide Giralt, que insiste en que la desconfianza e incluso el resentimiento habían cristalizado en 1868, cuando algunos pilotos se habían sumado al movimiento revolucionario; esto daba la sensación de que todo el colectivo estaba a favor de la abolición de las ordenanzas y esta creencia contribuyó a crear un cierto vacío entre ambas marinas ${ }^{47}$. Cuando en junio de 1901 se celebró el Congreso Marítimo, organizado por la recién creada Liga Marítima Española y con Adolfo Navarrete, Jefe de la Armada, como secretario, la mayoría defendió firmemente la unión de ambas marinas ${ }^{48}$. La opción contraria (la progresiva desmilitarización) se reivindicó en las conclusiones del Congreso de Marina Mercante que se celebró entre el 26 y el 31 de diciembre de 1902 en Gijón, y que fue organizado por asociaciones profesionales. El debate continuaba abierto y desde entonces constó en los programas de la mayor parte de las asociaciones profesionales y de los sindicatos hasta $1992^{49}$.

La Liga Marítima Española representó un papel fundamental en los intentos de conciliación entre ambas marinas. Constituida en 1900, agrupaba diferentes intereses bajo la idea de recuperar el poder naval y marítimo del pasado, a través del apoyo estatal a la Marina, y del hermanamiento entre la Marina mercante y la de guerra. En años precedentes se habían constituido instituciones similares en otras naciones, todas con un carácter similar en apoyo de sus respectivas marinas mercantes, pero sobre todo militares: Reino Unido (1894), Alemania (1898) y Francia, Italia y Bélgica (1899). La LME tuvo un gran protagonismo en el desarrollo de la legislación proteccionista de principios del siglo XX. Como señalaba Martín Rodrigo, su capacidad para ofrecer un único discurso de cara a la opinión pública y a los poderes ejecutivo y legislativo, así como para conseguir convertirse en una verdadera casa común para diferentes sectores empresariales, ayuda a explicar las ulteriores conquistas de la Liga Marítima, especialmente la Ley de la Escuadra de 1908 y la Ley de Comunicaciones Marítimas de $1909^{50}$. Además, la Liga se atri-

46 CONCAS, 1900: 488-491.

47 RICART, 1901a.

48 RICART, 1907:652-53.

49 Boletín náutico. Órgano de la Asociación Náutica Española, núm. 8, 1 de febrero de 1903. Más detalles en ZAMORA, 2003.

50 Sobre esta institución véase: Proyecto de la Liga Marítima Española, aprobado por su Junta Central con fecha 26 de enero de 1903. Madrid: [s.n.]; Manual de la Liga Marítima 
buía el papel de mediador para facilitar el entendimiento entre los diferentes agentes sociales, incluidos los conflictos de carácter puramente laboral ${ }^{51}$.

\section{Una imprescindible reorganización administrativa}

La dependencia de la Marina de guerra había quedado teóricamente matizada en parte con la creación, en abril de 1884, de una sección especial en el Ministerio de Marina denominada Junta de Marina Mercante ${ }^{52}$. Se trataba de un órgano consultivo presidido por un almirante y que contaba con la presencia de representantes del sector naviero y de profesionales, primero pilotos y capitanes, y a partir de 1893 también maquinistas ${ }^{53}$. Entre sus actividades se contemplaba proponer programas de exámenes para pilotos y maquinistas, revisar demandas de modificación de leyes, etcétera ${ }^{54}$. A la Junta de la Marina Mercante le sucedió la Dirección General de Navegación, Pesca e Industrias Marítimas (creada por decreto el 16 de octubre de 1901), que poco después pasó a denominarse simplemente Dirección de la Marina Mercante ${ }^{55}$.

En la primera década del siglo XX vislumbramos una profunda reorganización administrativa en la estela de la Ley de Protección y Fomento de las Industrias y Comunicaciones Marítimas de 14 de junio de 1909 (conocida en el ámbito marítimo como Ley Maura) y de la legislación desarrollada posteriormente. Esta norma marca una nueva forma de relación entre ambas marinas, con todos los matices posibles, como resultado de un primer proceso de reformismo social de gran peso. En una línea paralela un año antes, la Ley de Organizaciones Marítimas y Armamentos Navales de 7 de enero de 1908 (Ley Ferrándiz) pretendía reconstruir, tras el desastre de Cuba y Filipinas, una marina de guerra moderna, cuyas necesidades de personal se cubriría con un sistema de reclutamiento que no tendría el peso que tuvo la Matrícula durante los siglos anteriores.

Española. Cinco años de labor. 1900-1905, Madrid: Imprenta Alemana, 1906; RODRIGO, 2004:135-136. ARROYO, PÉREZ DE RUBÍN, ANCA, 2005. Sobre las relaciones entre la Liga Marítima Española y la Asociación de Navieros de Bilbao, véase VALDALISO, 1990:71-77.

51 NAVARRETE «Socialismo Marítimo», en Vida Marítima, núm. 40, 10 de febrero de 1903, 71-72.

52 Desarrollada por otras normas (Real Orden de 17 de junio de 1884 y Reales Órdenes de 13 de julio de 1895,17 de febrero de 1892 y 27 de agosto de 1893).

53 GARCÍA (2013)

54 Sobre la Junta véase El Mundo Naval Ilustrado, núm. 39, 10 de febrero de 1901, 517.

55 Copia del decreto en El Mundo Naval Ilustrado, núm. 64, 20 de octubre de 1901, 479482. Aparece un resumen de la historia de la Dirección de Navegación, Pesca e Industrias Marítimas en sus primeros años en Vida Marítima, núm. 106, 10 de diciembre de 1904, 672. 
Durante el proceso gestación de la ley Maura fue creado el organismo oficial que debía regular todo lo referente a la marina renovada: la Dirección General de la Navegación Marítima y Pesca Marítima, creada por una ley del 7 de enero de $1908^{56}$. Casi de inmediato, el 3 de febrero de 1909, bajo la presidencia del director general Emilio Luanco, se reunió por primera vez la Junta Consultiva de la Dirección General de la Navegación Marítima y Pesca Marítima, una sección que pretendía ofrecer un espacio de encuentro y discusión entre los diferentes agentes para la resolución de los problemas sociales y laborales. Se reunía anualmente y redactaba unos dictámenes que no eran vinculantes pero que debían influir en la producción legal del Estado. En ella había representantes de todos los estamentos implicados en la vida marítima civil del país: navieros, capitanes y pilotos, prácticos, maquinistas navales, patrones de cabotaje, marineros y fogoneros. También se sumaron a la Junta Consultiva instituciones como la Liga Marítima Española, la Junta Superior de Producción, la Junta Superior de Emigración y las Juntas Provinciales de Pesca. Pero no se debe olvidar que no se trataba de una mesa de discusión equilibrada. En palabras del abogado Hostench, «hay nueve obreros contra 16 elementos patronales, además de la representación del Ministerio, siendo la proporción existente de tres contra uno, llevando los obreros la minoría. ¿Qué ha de salir de las discusiones? ${ }^{57}$. La Junta Consultiva, que debía ser el principal instrumento de aplicación del reformismo en la marina, se reunió de forma periódica, y funcionó con relativa normalidad y un moderado éxito hasta la reorganización de los asuntos marítimos con la Segunda República, un breve periodo de marina civil, fuera ya de la acotación temporal estudiada ${ }^{58}$.

Un elemento significativo en relación con la reorganización administrativa y la desmilitarización es el fallido intento de dotar a la Marina mercante de un corpus legislativo único y ordenado a partir de un código específico para esta institución o de una Acta de Navegación capaz de articular todo lo que tenía que ver con el transporte marítimo en su globalidad (aspectos comerciales, sanitarios, aduaneros, de seguridad, diplomáticos, industriales, laborales, etcétera $)^{59}$. Las fuentes recurrentemente hacen referencia a la confusión, a las

56 Boletín de la Liga Marítima Española, núm. 86, septiembre-octubre de 1914, 7. Este organismo había tenido su antecedente en la creación en 1901 de la Dirección General de Navegación, Pesca e Industrias Marítimas (luego Dirección de la Marina Mercante), primer intento serio de vincular el elemento civil a un organismo todavía presidido por un militar.

57 HOSTENCH, 1922:23. Si se repasa la relación de miembros que constituían la Junta Consultiva en el verano de 1913, la realidad es más compleja y las proporciones entre los sectores representados es algo diferente. Datos completos en RODRÍGUEZ, 1915:306-308.

58 HERRÁN, 2000.

59 A menudo se utiliza esta denominación siguiendo la tradición de las Actas de Navegación británicas, leyes proteccionistas que desde la primera promulgada en 1651, organizaron dicha marina. Fuentes de inspiración fueron, sin duda, la Ordonnance de la Marine du mois d'aout 1681 o el Codice per la Veneta Mercantile Marina, publicado en Venecia en 1786. 
contradicciones e incluso a la imposibilidad material de conocer toda la normativa vigente en cada momento. Destacados juristas reconocían su impotencia ante el laberinto legal en el que se desarrollaba la Marina mercante española. De aquí que una de las principales preocupaciones de los implicados, a lo largo de todo el siglo XIX fuese la unificación legislativa y la dirección de la Marina mercante desde una administración civil y no militar, tomando como modelo el Board of Trade británico, que asumió la mayor parte de competencias sobre la marina civil desde 1850. La codificación del derecho marítimo debía representar para España un instrumento de normalización en el sentido que habían tenido el Código Penal de 1822, el Código de Comercio de 1829, o tendría el tardío Código Civil de 1889.

Existen unos antecedentes de intencionalidad puramente ordenadora, enmarcados en el Antiguo Régimen y sin ningún interés por separar lo militar de lo civil. Se trata del proyecto titulado Ordenanza General para la Marina Mercantil de 1778, que no llegó a promulgarse (y que en gran parte era una síntesis de la legislación anterior, articulada sobre el eje de las Ordenanzas del Consulado del Bilbao $)^{60}$ y de la propuesta presentada a las Cortes hacia 1813 por el capitán de navío Francisco Basurto ${ }^{61}$. El interés por la codificación germina realmente en plena ofensiva liberalizadora. Entonces se busca una referencia en modelos extranjeros, y sin duda uno de los ejemplos utilizados es el de Italia, nación de nuevo cuño, donde regía un código de la marina mercantil que databa del 25 de junio de 1865. A partir de aquí encontramos propuestas diversas que, además de ordenar el derecho, plantean la conveniencia o no de separar ambas marinas: por ejemplo, la redactada por la asociación profesional Fomento de la Marina Española, en 189462, la lanzada desde Bilbao en $1900^{63}$, una propuesta muy elaborada de la Liga Marítima Española en $1901^{64}$, etcétera. Pero el camino abierto por la Ley Maura de 1909 y el despliegue legislativo que la precedió y la siguió aparcaron las discusiones sobre este asunto.

60 AGMAB, Navegación mercantil. Asuntos particulares. Los comentarios en ALFONSO, 1995:175-176.

${ }_{61}$ Memoria y proyecto sobre arreglo de la Marina mercante, presentado a las Cortes por la Comisión nombrada al efecto y observaciones del capitán de navio D. Francisco Basurto. 1812-1813. Capítulo 3, 362-397. AMNM, manuscrito 0445/003.

62 Revista General de la Marina Militar y Mercante Española, núm. 51, 20 de enero de 1895, 746-748 y núm. 55, 10 de marzo de 1895, 805. El Fomento de la Marina Española había aprobado en su Junta General de 31 de diciembre de 1893 un proyecto de Acta de Navegación que elevó a las Cortes para su estudio. En fecha 11 de enero de 1894 se remitió a la Cámara un ejemplar para su estudio y posterior comentario, pero no prosperó (en AHCOCINB, expediente 72-20).

${ }^{63}$ Para un código de la Marina mercante española. Bilbao, Imprenta y Librería de José de Astuy, 1900.

${ }^{64}$ Ante-proyectos de Código Marítimo Civil y Ley de Pesca Marítima. Madrid, Imprenta Alemana, 1905. 


\section{El reformismo y la legislación social en la marina}

De la misma forma que en otros campos de la economía, en las industrias marítimas se plantearon propuestas reformistas que buscaban atenuar el choque entre las clases. A los efectos ya conocidos y descritos de la industrialización, en la mar deben añadirse los propios del paso de una economía preindustrial basada en los buques de vela y madera a una economía totalmente industrial fundamentada en buques metálicos, de propulsión mecánica y con una organización del trabajo distinta. Por tanto el reformismo en la marina mercante tiene un desarrollo paralelo al de tierra y se focaliza en problemas muy concretos. En la nación marítima más importante del mundo, Gran Bretaña, la Navigation Act de 1850 estableció los cimientos de todo un aparato legislativo de carácter social ${ }^{65}$. La influencia del reformismo social llegó a la Marina mercante española mucho más tarde, a caballo del cambio de siglo, en el contexto de una reforma profunda del sector marítimo que pivotaba alrededor de la citada Ley de Comunicaciones Marítimas de 1909. Este movimiento se había consolidado en España a finales del siglo XIX, y en él confluyen, según Palacio, «el reformismo de inspiración krausista, las distintas corrientes del catolicismo social y las posturas más conservadoras que acaban por aceptar la complejidad de la cuestión social, y la necesidad de un cierto intervencionismo estatal en el campo de lo social ${ }^{66}$. El reformismo social, que confiaba en que a través de la educación y la salud física y moral de la clase obrera se podía llegar a conseguir una convivencia armónica entre las clases, se institucionalizó en España en sus inicios con la creación de la Comisión de Reformas Sociales, en 1883 (Real Decreto de 15 de diciembre), y a partir 1903 con la puesta en marcha del Instituto de Reformas Sociales (Real Decreto de 28 de abril).

Los primeros resultados importantes en cuanto a legislación positiva en el sector marítimo fueron el Reglamento sobre Contratación de las Dotaciones por un lado, y el Reglamento de Policía y Disciplina a bordo de los Buques Mercantes Españoles por otro, ambos promulgados en 1909. Pero pese a estos cambios y la existencia de abundantes disposiciones en forma de real decreto, real orden, reglamento o jurisprudencia, las actividades marítimas españolas se desarrollaban en la segunda década del siglo XX en un marco legislativo caótico e irracional, que impedía el despegue de una Marina mer-

65 Su desarrollo se había iniciado antes, en 1836, con la constitución del British Parliament's Select Committee on Shipwreck, de carácter humanitario. En general este proceso legislativo vino precedido de una presión de tipo filantrópico sobre los diferentes gobiernos. Para detalles de este importante proceso en Inglaterra, véase WILLIAMS, 2000, y DIXON, 1981. Las consecuencias del reformismo victoriano alcanzaron a las marinas de todo el mundo de forma directa o indirecta.

66 PALACIO, 1986:273. 
cante moderna y competitiva. El sector estaba regulado en España con la intervención de seis ministerios, que se ocupaban de diferentes áreas concernientes a las actividades marítimas: Marina (jurisdicción, vigilancia, policía, disciplina, abanderamiento, seguridad en la navegación, enseñanzas náuticas, etcétera.), Fomento (todo lo relativo al tráfico marítimo sensu stricto), Instrucción Pública (enseñanzas náuticas en parte), Gobernación (Sanidad Marítima), Estado (consulados) y Hacienda (aduanas) ${ }^{67}$. A partir de 1920 se añadiría a estos seis ministerios todavía un séptimo con atribuciones en el campo de las relaciones laborales: el Ministerio de Trabajo. Pero por encima de los organismos civiles, existía siempre la sombra de una supervisión de la Armada, más discreta o más visible según el momento.

En otro nivel debemos considerar que, a partir de 1914, la coyuntura de la Gran Guerra alteró el escenario del sector marítimo mundial (también del español) y con la paz se produjo el despliegue de una legislación laboral de carácter internacional. Una de las consecuencias del Tratado de Versalles, de 28 de junio de 1919, fue la creación de la Oficina Internacional del Trabajo. En este marco debemos situar la Conferencia Internacional del Trabajo, celebrada en Washington entre octubre y noviembre de 1919. Poco después, en junio de 1920 se celebró en Génova una reunión sectorial, la Conferencia Internacional de los Marinos, dependiente de la OIT. A partir de ahí se caminó hacia una ordenación internacional del trabajo en la Marina mercante, que también afectó a España ${ }^{68}$. El Código de Trabajo de 1926 recogió gran parte de estas novedades, también en cuanto al trabajo en la mar, y la proclamación de la II República abría la puerta a reformas estructurales de más calado con la ley de 12 de enero de 1932. Sin embargo, la creación de una marina civil no tuvo apenas oportunidad de desarrollar una tarea legislativa progresista, y el principio de la guerra civil acabó con cualquier esperanza en este sentido. Habrá que esperar hasta 1992 para que España organice su marina mercante de forma totalmente liberada de la influencia militar ${ }^{69}$.

De todo lo descrito hasta ahora, tal vez el elemento que debamos destacar por encima de todo es que cualquier reforma administrativa buscaba no solo una mejora en el funcionamiento de la administración marítima, sino también decantar hacia lo civil la regulación de las actividades marítimas. Evidentemente, se trata de un intento de escaso éxito, ya que dependía en gran parte del poder político civil frente a un poder fáctico militar que no ha dejado de influir en la historia contemporánea de España y que no ha permitido hasta tiempos muy recientes una total independencia de la tutela militar.

67 ANASTASIO, 1918:7-8.

68 Conferencia Internacional de los Marinos, celebrada en Génova el 15 de junio de 1919. Memoria. Madrid: Sociedad Española de Artes Gráficas, 1920.

${ }^{69}$ Ley 27/1992, de 24 de noviembre, de Puertos del Estado y de la Marina Mercante. 


\section{FORMAS DE CONTROL Y SUPERVISIÓN DEL TRABAJO Y LOS TRABAJADORES}

En los párrafos anteriores se ha descrito la relación entre la marina mercante y la de guerra en España, sus causas y los procesos que intentaron incrementar la independencia de la marina mercantil. Para ello se ha focalizado en un aspecto concreto que es el mundo del trabajo y de las relaciones laborales. A continuación citaré algunos ejemplos concretos de esta influencia, dependencia, control y supervisión, según sea el caso. En todos ellos se puede percibir no solo cómo una actividad privada comercial quedaba sujeta a unas reglas que no son exclusivamente las del mercado o de los ciclos económicos, también que el valor estratégico del sector lo condicionaba como a ningún otro en tierra. No se trata de una relación exhaustiva, ni mucho menos, sino de una selección de situaciones que demuestran claramente del poder de la «Hermana mayor» sobre una tutelada marina mercante.

\section{Reserva de trabajo y jurisdicción especial}

Uno de los elementos definitorios de la Matrícula de Mar es la reserva de trabajo, establecida por primera vez en la Ordenanza de 1737. La existencia de un «closed shop» para un determinado grupo condiciona el mercado laboral y tiene efectos (en general positivos pero también negativos a veces) sobre el colectivo privilegiado. En el caso de las actividades marítimas, el Estado se arrogó la potestad de permitir el trabajo en la navegación, la pesca, la construcción naval y el trabajo portuario solo a quienes se comprometían con el servicio en la Marina de guerra. Con estas normas se establecían restricciones para el ejercicio de los oficios marítimos a los no matriculados ${ }^{70}$. Sobre esta base, la matriculación era formalmente voluntaria, aunque los opuestos a este sistema restrictivo aseguraban que los marinos no eran más libres de rechazar el contrato de la matrícula que el esclavo el contrato de la esclavitud o el siervo el contrato de la servidumbre. ${ }^{71}$ Durante más de 150 años solo los matriculados pudieron dedicarse a actividades marítimas. Y aunque la Matrícula fue abolida en 1873, hay insinuaciones de que años más tarde todavía se daban casos en que las Autoridades militares de Marina ponían dificultades al trabajo de personas que no consideraban «gente de mar» ${ }^{72}$.

70 Se comentan ejemplos en FERRET, 1819:108 y ss.

71 CORROZA, 1865:45.

72 Reformas sociales: Información oral y escrita publicada de 1889 a 1893. Tomo V. Información oral y escrita practicada por la Comisión de Reformas Sociales de Oviedo. Sesión de 19 de octubre de 1884, 403; NARIZ DE LA BARCA, 1900: 8. 
Otro de los elementos característicos de la Matrícula era su dimensión jurídica, manifestada en el denominado Fuero de Marina, instaurado en 1751, que situaba a la gente de mar en un estatuto diferente al del resto de los trabajadores. Esta jurisdicción especial se presentaba como una protección a la gente de mar en tanto que reserva de la Armada. También era considerada como un privilegio que el Estado concedía a cambio de los servicios presentes y futuros. Desde el momento de su inscripción, el matriculado (y también sus familias) quedaba a todos los efectos bajo jurisdicción militar. Esta situación se prolongó hasta que un decreto de 6 de diciembre de 1868 abolió las Jurisdicciones Privilegiadas, entre ellas las de Marina, poco antes de la abolición definitiva de la institución de la Matrícula.

\section{El fantasma de las campañas}

Los hombres hábiles o aptos para el servicio militar se organizaban territorialmente siguiendo un esquema semejante al de las Milicias Provinciales de Infantería: Departamentos, Tercios Navales, provincias marítimas o partidos, distritos y finalmente cuadrillas o «trozos». Mientras una cuadrilla estaba en campaña (movilizada), otra quedaba sujeta a embargo, es decir, sus movimientos se hallaban limitados a las aguas de su provincia y puertos inmediatos. Una tercera cuadrilla estaba en reserva pero gozaba de amplia libertad de movimientos, y solo la cuarta estaba, en principio, totalmente libre de obligaciones. Si llegaba el día en que eran llamados a campaña, eran embarcados en buques de la Armada y abandonaban por completo a la familia ${ }^{73}$. Más allá de las restricciones a la movilidad de la fuerza de trabajo, de la excesiva duración de las campañas (no eran excepcionales los servicios de incluso 10 años) y de la tardanza en el cobro de los sueldos, deben tenerse en cuenta los efectos económicos de más calado sobre el mercado laboral, así como el impacto demográfico que ocasionaba en los pueblos costeros la ausencia de tantos varones jóvenes, sin olvidar el impacto de cientos de muertos (en combate y,

73 Las ordenanzas les permitían que destinasen una parte de su sueldo a sus mujeres, hijos, padres o hermanos huérfanos. Además, al partir se les entregaba a los matriculados el equivalente a tres pagas para que dejaran a sus familias socorridas (Ordenanza de S. M. para el régimen y gobierno militar de las Matrículas de Mar, 1802, título XIII). En los alegatos contra la Matrícula abundan las referencias a padres ancianos e hijos menores abocados a la indigencia, y de mujeres condenadas a la prostitución. Véase Memoria sobre los vicios de que adolece la ordenanza de Matrículas de Mar de 1802....., 32-33. En otro documento se habla de «jóvenes esposas impulsadas por la miseria a sendas de perdición» (Exposición dirigida al Excmo. Sr. Ministro de Hacienda, por la comisión nombrada por todas las clases de Santander ..., 30). 
sobre todo, por enfermedades), cautivos e inválidos, muchos de los cuales a menudo no podían volver a trabajar en la mar $^{74}$.

\section{Un tema capital: el problema de la disciplina}

Cuando los trabajadores de la mar, con su actuación personal, ponían en cuestión el orden establecido, ya fuera en tierra o a bordo, se producían conflictos que podían ser calificados de delitos o faltas en función de su gravedad, en una situación de sometimiento a la ley infrecuente en otros sectores económicos. Para el caso español, en el siglo XIX y parte del XX la disciplina estaba regulada por el Título XIV de la Ordenanzas de $1802{ }^{75}$. Esta norma y las que la siguieron dieron a España un carácter especial a consecuencia de la intensidad del control estatal y de la supervisión por parte de la marina de guerra. El orden y la disciplina a bordo eran asuntos militares, en una situación que más tarde, en un contexto diferente (durante el franquismo) sería calificada como «estado de excepción permanente en la mar» ${ }^{76}$.

Las Ordenanzas eran de obligado conocimiento y cumplimiento, y el capitán debía leerlas en el momento de la firma de la contrata, como forma de coacción y recordatorio del sistema represivo en vigor. Este marco legal riguroso, junto un orden jerárquico estricto, unas normas no escritas de control social, y la figura del capitán como máxima autoridad a bordo, constituían los pilares para el mantenimiento de la convivencia y la disciplina a bordo. La abolición de la Matrícula de Mar en 1873 no supuso ningún cambio desde el punto de vista disciplinario, ya que una Real Orden de Marina de 16 de marzo de 1878 declaró vigentes todos los artículos del Título XIV y no hubo producción legislativa nueva en este campo hasta la promulgación del Reglamento de disciplina y policía a bordo de los buques mercantes españoles de 18 de noviembre de 1909, que modificó sólo en parte esta esquema de justicia militar. No exageraba quien escribía en 1914 que «el sistema de enjuiciamiento de la Marina mercante, hoy quizás [es] el más anticuado del mundo, ya que es preciso recurrir a cada momento en el mismo a preceptos legislativos del siglo XVIII» ${ }^{77}$.

74 VÁZQUEZ LIJÓ, 1997:119-123 y 126.

75 Ordenanza de S. M. para el régimen y gobierno militar de las Matrículas de Mar. Madrid: Imprenta Real, 1802.

${ }^{76}$ Sindicato Libre de la Marina Mercante. Proyecto de Código de Conducta y Ley Penal de la Navegación Marítima. Cuadernos de formación sindical, núm. 6, septiembre de 1978.

77 LICENCIADO AGUILERA, 1914:63. En AGMAB se encuentra abundante documentación sobre este asunto. Es interesante, por ejemplo, ver las denominadas Estadísticas Criminales, donde aparecen relacionados asuntos que implican a marinos mercantes y que son instruidos y juzgados por la Armada. 
Uno de los elementos que ilustra mejor el control sobre la fuerza de trabajo es el fenómeno de la deserción. El abandono del buque era una reacción ante una situación injusta o inconveniente, una forma de protesta o una reacción ante el mal trato, la mala comida, los salarios insuficientes o cualquier motivo de índole personal. También era muchas veces la huida del servicio militar o la mera busca de oportunidades en tierra o en otro buque mejor. Pero la deserción no era considerada simplemente una falta, equivalente al absentismo laboral o al abandono del puesto de trabajo: era un delito que se juzgaba por lo militar y se castigaba con dureza. Los desertores eran perseguidos, acosados y embargados para responder con sus bienes de los gastos del procedimiento (y también de la detención y el transporte) ${ }^{78}$. La normativa relacionada con la deserción era aplicable también en caso de huelga. Por ejemplo, con motivo de la huelga marítima en el año 1904, los navieros españoles exigieron al Gobierno que las autoridades de Marina aplicasen las disposiciones entonces vigentes relacionadas con el abandono de los buques por parte de las tripulaciones ${ }^{79}$. Esta militarización de una actividad laboral representaba una situación anómala contra la que se levantaron voces diversas. ${ }^{80}$ Se dio un tímido avance con el Reglamento de Policía y Disciplina a bordo de los Buques Mercantes Españoles de 1909 pero se mantuvo el carácter militar en las siguientes normativas: la Ley Penal de la Marina Mercante de 1923, y la Ley Penal y Disciplinaria de la Marina Mercante de 1955, derogada de facto en 1978. Hasta entonces el fantasma del delito de deserción fue un arma eficaz contra la movilización obrera.

\section{Supervisión de los contratos}

En 1748 y como nuevo instrumento de supervisión del Estado se instituyó la figura del «Escribano de Marina», un notario especializado ante el cual se

78 Dos expedientes completos en ACA, Diversos, Comandancia de Marina de Barcelona: Expediente 38. Ramo separado para el embargo de bienes de José Font y Roldós, marinero de la Matrícula del distrito de Masnou [...] dimanado de la causa que se le forma por deserción de un buque mercante en América, por valor de 500 pesetas; Expediente 25. Causa contra el marinero Miguel Fiol y Sabater, de 20 años, natural de Barcelona, por deserción de la fragata mercante Bella Juana en Nueva Orleans, y ramo separado para el embargo de bienes por valor de 300 escudos, además de pena de dos campañas extraordinarias (1869). Dos casos más, entre mucho otros, en AGMAB, Departamento de Ferrol. Justicia. Núm. 204. Causa contra Juan Blanco Riveira, desertor del bergantín Paco en La Habana. F8124; Navegación Mercantil. Alfabetizado de marinos, Expediente 19, 7144/2.

79 AHCOCINB, caja 72, expediente 23. También: Vida Marítima, núm. 74, 20 de enero de 1904, 33.

80 Por ejemplo, LICENCIADO AGUILERAS, 1904:130; CORA, 1905:230-231. 
protocolizaban todo tipo de documentos relacionados con la actividad marítima, incluidos los contratos de tripulación. Dichos contratos eran presentados luego ante las autoridades de Marina en las propias Capitanías o en los consulados, de forma que si bien mientras duraba el viaje era imposible la tutela, la Administración ejercía una supervisión previa y posterior sobre la relación laboral. Así, el marino entraba en el engranaje disciplinario desde el mismo momento en que el contrato se leía ante el Comandante de Marina (como representante del Estado). La promulgación del Código de Comercio el 30 de mayo de 1829 abrió la puerta a la formalización del contrato sin pasar por el trámite tradicional de las Escribanías de Marina, pero el control por parte de la Marina de Guerra persistía en otros niveles.

También en relación con la contratación y el control de la Armada, constituía un lugar común afirmar que las tripulaciones españolas eran más numerosas y más caras que las marinas extranjeras. Diversas fuentes coinciden en este extremo e intentan dar una explicación ${ }^{81}$. Aunque la respuesta es básicamente técnica ${ }^{82}$, existen indicios de que las Autoridades de Marina presionaban para que se embarcasen más marinos de los necesarios, tal vez para proteger los intereses de un colectivo que era vital para la defensa de la nación.

Las Comandancias de Marina no permiten la salida de los buques mientras no lleven una tripulación muy numerosa que de ninguna manera exigen las ordenanzas de Matrículas de mil ochocientos dos, y que tampoco hacen indispensable las necesidades de la embarcación que sale a viaje, según lo acredita la experiencia diaria en los buque extranjeros que suelen llevar siempre una tercera parte menos de tripulantes $[\ldots]\rangle^{83}$.

La Marina de guerra tendía a cuidar de una gente que en cierto modo consideraba más suya que del libre mercado, aunque formalmente la ley dejaba a los armadores total libertad para fijar el número y calidad de sus tripulaciones.

81 Baste el ejemplo de las diversas respuestas a la Información sobre las consecuencias... Tomo I. Derecho diferencial de bandera. Son de este parecer: las sociedades de vapores M. Sáenz y Cia. y Vinuesa y Cia. de Sevilla, 45-46; el Centro Mercantil e Industrial de Gerona, 90; los Señores Llort y la Compañía de Barcelona, 334; la Junta Provincia de Agricultura, Industria y Comercio de Guipúzcoa, 340; y la Real Sociedad Económica de Amigos del País de Gerona, 354; Consejo Superior de Agricultura, Industria y Comercio, 419-420, pregunta 4. . . Según Valdaliso, las quejas de los navieros españoles eran ratificadas por fuentes extranjeras: «Each Spanish ship employed one man for every 4 tons. Each foreign ship employed one man for every 17 tons» (VALDALISO, 1991:92).

82 GARCIA, 2013: 68-69.

83 BC, Fondo de la Junta de Comercio de Barcelona. Juntas Provinciales de Agricultura, Industria y Comercio. Expediente 3. Informes y Servicios. 1886. JC 246-11. Respuestas al interrogatorio dirigido a los armadores o navieros, respuesta 2 . $^{\mathrm{a}}$ 


\section{El gremio como instrumento de control}

La reglamentación de las Matrículas de mar (en 1751) y el Reglamento de Matrículas de Muñoz (de 1785) tuvieron una repercusión directa sobre los gremios de mareantes, que fueron perdiendo poco a poco su carácter privado original para convertirse en organizaciones paraestatales, a diferencia del resto de gremios terrestres. Sus reuniones eran presididas por la autoridad de Marina, que incluso intervenía en los asuntos internos, anulando la personalidad del gremio. Las Ordenanzas de Matrículas de Mar de 1802, en su artículo 10, Título 5, fijaron definitivamente su carácter. Los gremios de mareantes quedaban desprovistos de cualquier función organizativa o de control, y simplemente se esperaba de ellos que cumplieran una función asistencial o religiosa. Los gremios, como institución propia del Antiguo Régimen, estaban en contradicción con los nuevos esquemas del capitalismo industrial y su propia decadencia fue acelerada por un acoso continuado por parte del Estado. El proceso de abolición de los gremios de mar fue lento y complejo. Por su interés estratégico la Armada consiguió mantener el modelo pre liberal en el sector marítimo ${ }^{84}$. Sin embargo, el proceso iniciado era ya irreversible y el 9 de julio de 1864 un decreto ${ }^{85}$ determinaba su extinción definitiva y su liquidación como compañías o sociedades.

\section{La Justicia militar aplicada a abordajes y naufragios}

La figura del capitán de un buque es una figura compleja, en sus diversas dimensiones como gerente del barco como centro de trabajo, como representante del armador, y también como representante del Estado. A estas atribuciones hay que sumarles las funciones derivadas de la aplicación de las Ordenanzas de Matrícula y vinculadas a la disciplina militar naval y del Fuero de Marina. En su posición, el capitán era el máximo responsable de la navegación, del buque y de la carga. Así, por ejemplo, en caso de accidente marítimo, se abría un procedimiento judicial militar, lento y complicado, que entre otras cosas, podía mantener desembarcados a los capitanes durante meses sin posibilidad de trabajar y obtener ingresos hasta que se dictaba sentencia. Sobre este asunto comentaba un autor anónimo: «si llegase a sufrir con su buque alguna avería, cosa que sabe no es difícil en nuestra carrera [el capitán] probablemente sería empapelado durante diez y seis o veinte meses, haciendo

84 Véase una comunicación del comandante general del Apostadero de Cartagena de 10 de junio de 1834 en IBARZ y ROMERO, 2009:257.

85 Decreto de abolición de los gremios, de 9 de julio de 1864 (en Gaceta de Madrid, 13 de julio de 1864). 
viajes de la Comandancia al Departamento [...] y quedando su familia durante ese tiempo que está empapelado esperando a que llueva aquel maná del cielo para poderse mantener» ${ }^{86}$.

\section{Control de las titulaciones náuticas}

La regulación de los estudios náuticos se había desarrollado a partir de la Instrucción de Winthuysen (1790), que establecía unos estudios teóricos y un proceso de exámenes a realizar ante oficiales y Jefes de la Marina de guerra. Este esquema se mantuvo durante décadas, prácticamente hasta la etapa final de la marina de vela ${ }^{87}$. Pero fue recurrente la indefinición entre la Marina civil y la militar, que llevó por ejemplo a que los estudios dependieran de la autoridad civil pero los exámenes y las titulaciones fueran atribución de la Marina de guerra, legislando ambas esferas con absoluta independencia, de forma que se producía un gran confusión en la instrucción del personal ${ }^{88}$ que no fue resuelta hasta la aprobación del Reglamento de Enseñanzas Náuticas de 28 de mayo de 1915. Fue entonces cuando por primera vez se separaron claramente las funciones civiles de las militares. El Ministerio de Instrucción Pública sería el responsable de la enseñanza, pero el de Marina ejercería el control final. Es decir, cuando el estudiante acababa los cursos, recibía un certificado de estudios como alumno de náutica o alumno de máquinas. Con él, los aspirantes debían inscribirse en las Comandancias Militares de Marina, momento en el que rompían su relación con la administración civil, podían realizar sus prácticas, y al finalizar estas pasaban el correspondiente examen en las Comandancias competentes ${ }^{89}$.

86 El Mundo Naval Ilustrado, núm. 34, 20 de diciembre de 1900, 541-542. Un caso detallado de juicio en FERNÁNDEZ REPETO (1928). Pueden consultarse también multitud de sumarios completos de este tipo en el Archivo General de Marina. Por ejemplo: Departamento de Ferrol. Año 1872. Mayoría General núm. 891. Proceso con motivo de la varada de la barca [corbeta] San Fernando el 24 de diciembre de 1869 en el bajo Bennet de las Islas de Sibuyan y Masbate. Acusado: D. Manuel Garnecho, capitán de dicho buque. AGMAB, 8544 Departamento de Ferrol. Absuelto por sentencia de 22 de junio de 1872.

87 Instrucción general para la disciplina, Estudios y Exámenes que deben seguirse en las escuelas reales y particulares de Náutica del Reino, publicada el 26 del mismo mes bajo el título Método de Estudios y Certámenes para las Escuelas Reales de navegación y particulares del Reino. Más detalles en GARCIA (2013).

88 Sobre este asunto véase GARCIA (2014)

89 Sobre el caso de los maquinistas, véase GARCIA, 2013. 


\section{CONCLUSIÓN}

El marco legislativo en el que se desarrolla la Marina mercante española entre los siglos XVI y XX fue un claro reflejo de la supeditación del sector marítimo a las necesidades de la Marina de guerra, con todas las consecuencias que esto tuvo para el colectivo afectado, la gente de mar. Desde el punto de vista del trabajo y las relaciones laborales, que es el enfoque utilizado en este artículo, el instrumento básico de organización y control de la gente de mar fue la Matrícula de Mar, creada en 1606, que alcanzó su cenit en 1802 y que fue abolida definitivamente en 1873, aunque su influencia continuó notándose durante décadas. Se trataba de un sistema que, para garantizar el suministro de hombres para la Armada (para la tripulación, pero también para completar el personal de los astilleros, etcétera), exigía un registro de todos aquellos que desearan trabajar en la mar, pues reservaba el monopolio de las actividades marítimas a los matriculados. Los efectos de la Matrícula (reserva de trabajo, mediatización del mercado laboral, sometimiento del trabajo a las necesidades de la defensa nacional, control de la disciplina, jurisdicción especial por medio del Fuero de Marina, entre otros) explican gran parte de las características del trabajo en la Marina mercante. La Matricula forjó un sistema de relaciones entre la marina civil y la militar que perduró mucho más allá de la abolición de aquella institución del Antiguo Régimen. En cierto modo, esa dinámica no se pudo romper hasta 1932 en un intento truncado por la guerra civil.

La supeditación de la marina mercante a la Armada forzó a las actividades marítimas a desarrollarse en un marco legal confuso y a veces contradictorio, disperso y falto de unidad, que pudo haberse corregido con un código de la Marina mercante que nunca llegó a promulgarse. Gran parte de la responsabilidad de esta situación la tuvo la injerencia de la Marina de guerra en un sector económico que se regulaba también desde otros ministerios (Hacienda, Fomento, Gobernación, etcétera). Esta circunstancia era fuente de continuos conflictos entre jurisdicciones, los cuales obviamente repercutían en el mundo del trabajo, entre otros. Sobre la influencia de lo militar sobre el trabajo y los trabajadores se han presentado algunos ejemplos que muestran el alcance de esa supervisión sobre aspectos puramente laborales y, por tanto, civiles.

El poder de la Armada sobre el sector marítimo continuó con la Dictadura de Primo de Rivera. Luego durante la II República, en 1932, se produjo un intento fallido de separar ambas marinas, pero a partir de 1936 la excepcionalidad de la guerra impidió cualquier avance. El poder de la Marina de guerra recuperó todo su esplendor con el franquismo, sobre todo en las dos primeras décadas, y finalmente coincidieron en el tiempo el final de la dictadura y el declive y la virtual desaparición de la marina mercante en los años ochenta, de forma que la difícil relación entre ambas marinas dejó de constituir motivo de conflicto: lo que quedó de actividad marítima quedó regulado a partir de 
1992 mediante una marina civil absolutamente liberada del control militar, aunque ya con poca cosa digna de ser controlada.

\section{BIBLIOGRAFÍA}

Anastasio Pascual, Ernesto, El personal de navegación. Su formación y reclutamiento. Los centros de instrucción marítima. Conferencia pronunciada el día 22 de febrero de 1918 en el salón de actos del Fomento del Trabajo Nacional bajo los auspicios de la Sociedad de Geografía Comercial de Barcelona, Barcelona, Establecimiento tipográfico de Mariano Galve, 1918.

Arroyo Ruíz-Zorrilla, Ricardo; Pérez de Rubín, Juan; Anca Alamillo, Alejandro, La Real Liga Naval Española. Breve historia de su creación y de sus primeras iniciativas en defensa de la España Marítima, Madrid: Palafox \& Pezuela, D. L., 2005.

Bonamusa, Francesc; Serrallonga, Joan, Del roig al groc. Barcelona, 1868-1871. Quintes i epidèmies, Barcelona, L'Avenç y Diputació de Barcelona, 1995.

Castillo, Santiago, «Todos iguales ante la ley... del más fuerte. La legislación laboral y los socialistas españoles en el cambio de siglo (XIX-XX)» en Sociología del Trabajo, núm. 14 (1991-1992), 149-176.

Cepeda Gómez, José, «La historiografía sobre la marina en los siglos XVIII y XIX» en La historiografia de la marina española. Cuadernos monográficos del Instituto de Historia y Cultura Naval, 56, Madrid, 2008.

Chaunu, Pierre, Sevilla y América siglos XVI y XVII, Sevilla, Universidad de Sevilla, 1983.

Colldeforns Lladó, Francisco de Paula, Historial de los Gremios de Mar de Barcelona (1750-1865), Barcelona: edición del autor, 1951.

Concas, Víctor M., «La marina de guerra y la mercante», en El Mundo Naval Ilustrado, núm. 31, 20 de noviembre de 1900, 488-491.

Cora Cora, J., «Estudio acerca de la forma en que actualmente se contrata el embarque de tripulaciones», en Revista General de Marina, núm. 57, agosto 1905, 215234.

Corroza, Canuto, Estudios sobre una ley para el uso general del mar, para la navegación y para los puertos, Madrid, Imprenta de la viuda de D. J. Cosme de la Peña, 1865.

Costa, Joaquín: Marina española o la cuestión de la escuadra. Huesca: [s.n.], Tip. Leandro Pérez, 1912.

Dixon, C. H., Seamen and the Law: An Examination of the Impact of Legislation on the British Merchant Seaman's Lot, 1588-1918, tesis doctoral inédita, University College London, 1981

Escaño, Antonio, Ideas sobre un plan de reforma para la marina militar. Madrid: [s.n] 1820.

Fernández Duro, Cesáreo, La Armada española desde la unión de los Reinos de Castilla y Aragón, Madrid, Editorial Naval, 1973. 
Fernández Repeto, Joaquín, Defensa del capitán del vapor español «Eugenio Dotrus» Don Pedro Astoreca Monasterio ante el Consejo de Guerra con motivo de la varada del buque y posterior naufragio en la Playa de los Lances de Tarifa. Cádiz: [s. n.], 1928.

Ferret, Zeferino, Exposición histórica de las causas que más han influido en la decadencia de la Marina Española e indicación de algunos medios para restaurarla, Barcelona, Impreso por Roca y Gaspar. 1819

Gago González, José María, «Aproximación a la historia social: el trabajo y la vida cotidiana de los ferroviarios de movimiento y tracción en la RENFE: una historia oral» en IV Congreso de Historia Ferroviaria, Málaga, 20-22 de septiembre de 2006.

Garcia Domingo, Enric, El trabajo en la Marina Mercante española en la transición de la vela al vapor, 1834-1914. Tesis doctoral inédita. Universidad de Barcelona, 2013.

Garcia Domingo, Enric, «Losing professional identity? Deck officers in the Spanish merchant marine, 1868-1914», International Journal of Maritime History, vol. 26, no. 3 (agosto 2014) 451-470.

García-Baquero González, Antonio; Martínez Shaw, Carlos, Andalucía y la Carrera de Indias (1492-1824, Granada, Universidad de Granada, 1992.

Gutiérrez de la Cámara Señán, José Manuel «El factor clave: el personal» en Cuadernos de pensamiento naval. Suplemento de la Revista General de Marina, núm. 10, noviembre de 2009, 37-77.

Herrán, Raúl, La marina mercante en la II República española (1931-1939): la administración marítima. Vitoria: Servicio Central de Publicaciones del Gobierno Vasco, 2000.

Hostench, Francisco, El problema social de los marinos mercantes ante la crisis económica; lo que piden al Gobierno. Conferencia organizada por la Asociación de Capitanes y Pilotos de la Marina Mercante Española y por la Sociedad Española de Maquinistas navales; que dio la noche del 24 de febrero en los salones del Fomento del Trabajo Nacional el abogado de ambas entidades D. Francisco Hostench, Barcelona, Imprenta de Ángel Ortega, 1922.

Ibarz Gelabert, Jordi, Imatges al moll. Els oficis de les feines d'estiba a la Barcelona dels segles XIX $i$ XX, Barcelona, Generalitat de Catalunya, 2008.

Ibarz Gelabert, Jordi, Romero Martín, J. J., «L'abolició de la Matricula de Mar i les tasques de càrrega i descàrrega al port de Barcelona, 1868-1874», en Grau, Ramón (ed.); El tombant del 1868-1874. Seminari d'Història de Barcelona. Barcelona: Quaderns d'Història, 15. Arxiu Històric de la Ciutat de Barcelona, 2009.

Liga Marítima Española, Manual de la Liga Marítima Española. Cinco años de labor. 1900-1905, Madrid: Imprenta Alemana, 1906.

Lenhof, Jean Luis, «Voile ou vapeur. Étude sur le travail à bord des cargos longcourriers français de la fin du XIXe siecle (1880-1920)», en La Marine marchand française de 1850 a 2000. Revue d'Historie Marítime, núm. 5, 2006, 59-102.

Leygonier y Márquez, Cayetano, Asociación Nacional para el Fomento de la Marina. Estatutos, Madrid, Imprenta El Progreso, 1885. 
Licenciado Aguilera [seud.] (1904): «La deserción del marino mercante», en Vida Marítima, núm. 79, 10 de marzo de 1904, 130.

Llovet, Joaquim, La Matrícula de mar i la provincia de marina de Mataró al segle XVIII. Mataró, Rafael Dalmau, 1980.

López Miguel, Olga; Mirabet Cucala, Magda, «La institucionalización de la Matrícula de mar: textos normativos y consecuencias para la gente de mar y maestranza» en Martínez Shaw (ed.): El Derecho y el Mar en la España Moderna. Granada: Universidad de Granada y Centre d'Estudis d'Història Moderna Pierre Vilar, 1995.

Martín García, Alfredo, «Entre el mar y la muerte. Procedencias, condiciones de vida y mortalidad de los navegantes en el Real Servicio (1776-1804)» en Espacio, Tiempo y Forma, Serie IV, Historia Moderna, 12, 1999.

Martínez Shaw, Carlos, «Las flotas de Indias y la protección del tráfico atlántico bajo los Austrias», en Alcalá-Zamora y Queipo de Llano, José (coord.): La España oceánica de los tiempos modernos y el tesoro submarino español. Real Academia de la Historia, 2008.

Moreno Rico, Javier., El piloto de derrota José Ricart y Giralt (1847-1930) y la cultura marítima de su época. Barcelona, Museu Marítim de Barcelona, 2013.

Nariz de la Barca [seud.], Carta Marítima, Barcelona, Imprenta de Subirana Hermanos, 1900.

Navarrete, Adolfo «Socialismo Marítimo», en Vida Marítima, 40, 10 de febrero de 1903, 71-72.

Palacio, Juan Ignacio: «Crisis política y crisis institucional: la experiencia del Instituto de Reformas Sociales en el período 1914-1923» en García Delgado (ed.): La crisis de la restauración: España, entre la Primera Guerra Mundial y la Segunda República. Madrid: Siglo Veintiuno Editores, 1986, 271-289.

Pérez Mallaína, Pablo Emilio, Los hombres del Océano. Vida cotidiana de los tripulantes de las flotas de Indias. Siglo XVI. Sevilla: Servicio de Publicaciones de la Diputación de Sevilla - Sociedad Estatal para la Exposición Universal de Sevilla, 1992.

Ricart Giralt, José, «Los capitanes de la Marina mercante» en El Mundo Naval Ilustrado, 41, 28 de de febrero de 1901, (1901a) 87-90.

Ricart Giralt, José, «Los oficiales de la Marina mercante» en El Mundo Naval Ilustrado, 42, 10 de marzo de 1901, - (1901b): 106-108.

Ricart Giralt, José, «La militarización de la Marina mercante» en Revista General de Marina, tomo LXI, octubre de 1907, 641-664.

Rodrigo Alharilla, Martín, «Los dividendos de la presión política. La Liga Marítima Española (1899-1910) ». Revista de Historia Económica - Journal of Iberian and Latin American Economic History, 22/3, 2004, 707-734.

Rodríguez Jalón, Abelardo, Guía práctica o los reglamentos y disposiciones que regulan el funcionamiento de la Marina Mercante Española, Madrid, Imprenta del Ministerio de Marina, 1915.

Salas, Francisco Javier de, Historia de la Matrícula de mar y examen de varios sistemas de reclutamiento marítimo, Madrid, Imprenta de T. Fortanet, 1870. 
Sindicato Libre de la Marina Mercante. Proyecto de Código de Conducta y Ley Penal de la Navegación Marítima. Cuadernos de formación sindical, 6, septiembre de 1978.

Valdaliso Gago, Jesús María, «Política económica y grupos de presión: la acción colectiva de la Asociación de Navieros de Bilbao, 1900-1936» en Historia Social, 7, 69-10, 1990.

Valdaliso Gago, Jesús María, Los navieros vascos y la Marina mercante en España, 1860-1935. Una historia económica. Bilbao: Instituto Vasco de Administración Pública, 1991.

Vázquez Lijó, José Manuel, «Los privilegios de la Matrícula de Mar y su cuestionamiento práctico. La dureza del Real Servicio en la Armada en el siglo XVIII» en Obradoiro. Revista de Historia Moderna, 6, 107-130, 1997.

Vázquez Lijó, José Manuel, «Supervisión y control de los gremios de mar por las autoridades de marina: los cabos celadores y otras disposiciones de la Ordenanza de Matrículas de 1751» en VIII Congreso da Asociación Española de Historia Económica. Santiago de Compostela: [s.n.], 2005.

Vázquez Lijó, José Manuel, La Matrícula de mar en la España del siglo XVIII. Registro, inspección y evolución de las clases de marinería y maestranza. Madrid: Ministerio de Defensa, 2007.

Williams, David M., «Mid-Victorian Attitudes to Seamen and Maritime Reform: The Society for Improving the Condition of Merchant seaman, 1867» en Scholl, L. U. (comp.): Merchant and Mariners: selected maritime writings of David M. William, Research in Maritime History, 18. St. John's, Newfoundland: International Maritime Economic History Association, 2000.

Zalvide, Manuel de, Reglamento de navegación, pesca, carga y descarga, y govierno político y económico de los Gremios de Matrícula de Gente de Mar, y Maestranza de Mallorca. Formado en revista de Inspección celebrada de orden del Rey por Don Manuel de Zalvide, comisario Real de Guerra de Marina, y ministro inspector de Matrícula de las provincias del Departamento de Marina de Cartagena. Mallorca: oficina de Ignacio Sarrá y Frau, impresor del rey nuestro señor, 1773.

Zamora Terrés, Juan, Notas para una historia del movimiento obrero en la Marina mercante, Barcelona, Museu Marítim de Barcelona, 2003.

Recibido: $27 / 10 / 2014$

Aceptado: 01/04/2016 